\title{
A CASE OF LARGE AMOUNT OF LIQUOR AMNII.
}

BY JOHN H. GOODELL, M. D., OF MARSEILLES, ILL.

I was called, February 26th, at six P. M., to Mrs. M., five months advanced in her ninth pregnancy. She was a thin, spare woman, about thirty-five years of age. She had never had any trouble with her previous gestations, but since her last conception she had been ailing all the time. In January last she had been quite sick, and unable to be about the house since then. Half an hour before my arrival, while she was sitting by the window, she felt something give away and immediately fainted. She was carried into an adjoining room to her bed, leaving a large pool of water where she had fallen. She was conscious when I came. She told me that she was larger before the accident than she had ever been at term. I found her weak, pulse 100, small. The bed upon which she was lying was completely saturated with water, dripping also from some dependent under part into a vessel which was one third full. The floor was nearly covered with water. The uterus seemed as large as it would have been at four months, and contracted fairly upon its contents. Digital examination revealed a fotus at the ostium vaginæ, and $I$ found the head of another just outside the os uteri. By careful manipulation the second one was delivered without very much hæmorrhage. During the time occupied in delivery the patient had fainted so many times that I began giving her brandy, in a measure relieving her. I made several fruitless attempts to get away the placenta. She seemed to fail so rapidly that I sent for Dr. J. Montgomery. We determined to continue the brandy and ergot, of which I had already given two doses, and, as her residence was in a locality predisposed to septic influences, we thought the placenta should come away. It was accordingly removed with very little loss of blood. Frictions of mustard to the extremities had been kept up for some time, but to no purpose. Ears of corn, dropped into boiling water for a few moments and rolled in cloths, were then placed between her legs and up the sides of the body as far as the axillæ. The uterus contracted well under the stimulus of the ergot, but the pulse continued small, despite the artificial heat. She was evidently sinking, so I gave brandy subcutaneously, putting most of it under the skin of the body. Our efforts were fruitless. She died at 9.45 P. M., about four hours from the time she fainted at the window. I questioned her husband and daughter with regard to any accident or fall or anything of the kind that might throw light upon the case, but they said there was nothing of that description that they could remember during the pregnancy, to which the unfortunate termination could be attributed. The amniotic fluid was estimated at six quarts. My impressions are that that is a low estimate; the hæmorrhage was not over twelve ounces. My 
views of the case are as follows: The double fœtus required twice the ordinary amount of exertion of the uterus, which weakened it. When the foetal development went beyond the point of uterine tolerance, the membranes broke, the shock and comparatively slight hæmorrhage proving fatal.

\section{CASE OF ACUTE RHEUMATISM TREATED WITH SALI- CYLIC ACID.}

BY IRVING W. SMITH, M. D., CHARLES CITY, IOWA.

JANUARY 20th, Gertie C., a delicate child of eleven years, first noticed slight pain and swelling of one ankle, which increased so as to confine her to bed on the following day.

February 2 d. On this day she was first seen by the physician. Several joints were now affected, the back was painful, and any motion unbearable. Erythema nodosum appeared on the arms and legs. The patient was put upon the ordinary alkaline treatment, with Dover's powder to relieve pain at night, and at the end of a week was so much improved that medical attendance was discontinued.

February 29th. The physician was again called. For the last three or four days and nights she had suffered constantly from severe pain, crying out continually. She was now ordered salicylic acid, five grains to be taken in a wafer every hour.

March 1st. Free from all pain. She became so in about twelve hours after beginning the remedy, having taken some forty grains. The acid was continued till seventy grains were taken, within something less than twenty-four hours. The effects observed were profuse perspiration, the head at one time a little "whirly," no appreciable disturbance of the stomach. The result seemed magical.

After about a week slight pains returned. Ten five-grain powders were administered, with the same gratifying result as before.

April 1st. There has been no further relapse; the girl is now in excellent health ; her mother says she " never felt better in her life."

\section{RECENT PROGRESS IN OPHTHALMOLOGY.}

BY O. F. WADSWORTH, M. D.

Anatomy of the Lachrymal Canaliculi. - Heinlein ${ }^{1}$ examined these canals on horizontal and frontal sections through children's heads after the lime had been removed from the bones by acids. He divides the canaliculus into five parts: punctum lachrymalis, vertical portion, curved portion, horizontal portion, and the conjoined canal with the opening into the sac. The punctum lachrymalis opens into a vertical

1 Archiv für Ophthalmologie, xxi. 3. 